\title{
COVID-19 and male fertility: Taking stock of one year after the outbreak began
}

\author{
Rocco Francesco Delle Fave, Giordano Polisini, Gianluca Giglioni, Arnaldo Parlavecchio, \\ Lucio Dell'Atti, Andrea Benedetto Galosi
}

Division of Urology, University Hospital "Ospedali Riuniti”, School of Medicine, Department of Clinical, Special and Dental Sciences, Marche Polytechnic University, Ancona, Italy.

\begin{abstract}
Summary $\quad$ Objectives: The aim of this review is to summarize, following a timeline, the current knowledge regarding the effects of the Sars-cov2 virus on male fertility, researching the pathological and clinical results of the studies published in the last year.

Methods: A systematic research was performed on the major international online databases; Thirty-five articles were selected.

Results: A statistically significant reduction in testosterone levels and sperm quality in subjects with COVID-19 has been highlighted in several papers; however, in many cases the tests have been conducted in patients with active disease and long-term consequences are still not known. Some studies have confirmed the presence of the virus in the testis in a low percentage of patients; viral presence in sperm has only been found in one study. Testicular discomfort, which could indicate viral orchitis, was highlighted in several works, with an incidence of up to $19 \%$ percent of patients. The presence of inflammatory lymphocytic infiltrates, IgG and inflammatory cytokines have been documented in several works; pathological signs of inflammation were found in $60.9 \%$ of testicular biopsies performed in one study. The entry of the virus into the testis cells, both stromal and seminal cells appeared to be Angiotensin Converting Enzyme-2 (ACE2) mediated, as it also occurs in other tissues. DNA fragmentation, reactive oxygen species (ROS) formation, autoantibody production and ACE2 mediated effect have all been hypothesized as cause of cellular damage.

Conclusions: The results on effects of COVID-19 infection on the male reproductive system are currently insufficient as they are based on a small number of patients and therefore are often contradictory.Certain mechanisms of testicular damage are still to be assessed, as any risk categories like age, ethnicity, or others. As for the transmission of the virus through sperm, there is insufficient evidence to ensure that this cannot happen.
\end{abstract}

KEY WORDS: COVID-19; SARS-CoV-2; Male fertility; Infertility; Sperm.

Submitted 11 January 2021; Accepted 21 January 2021

\section{INTRODUCTION}

Coronaviridae are single-chain RNA viruses, with an envelope covered with spikes that give the viruses the typical "crown" appearance. There are four subtypes (alpha, beta, gamma and delta) and among these differ- ent species are responsible for zoonoses, infecting mammals such as bats, cats, dogs, various rodents (1), and eventually passing to humans.

Seven types of coronaviruses have been identified that have caused infections in humans so far; humanity has already challenged epidemics caused by these viruses, last of which were severe acute respiratory syndrome (SARS) in 2003 and Middle East respiratory syndrome (MERS) in 2012 (2).

In December 2019 in the Chinese town of Wuhan several cases of acute respiratory syndrome were reported; etiological agent was found to be Severe acute respiratory syndrome coronavirus 2 (SARS-COV2); infectious cases spread rapidly through continents.

Transmission occurs most frequently through droplets and contact but the virus has also been identified in saliva, faeces and urine $(3,4)$.

Lu et al. (5) first described the mechanism of infection: the virus binds to the angiotensin 2 converting enzyme (ACE2) through glycoproteins membrane S; the S1 domain deals with the binding with the host cell while the $\mathrm{S} 2$ domain is responsible for the fusion of the membranes undergoing a proteolytic priming by the transmembrane serine protease TMPRSS2(6) (Figure 1).

The ACE2 enzyme is strongly expressed in lung, kidney, cardiac, gastrointestinal, bladder and testicular cells (7). In the testis it is found in both in the cells of the seminiferous ducts, in particular spermatogonia, and in the cells of Leydig and Sertoli (8). Hence the hypothesis that the testicle may be a reservoir of the disease. The aim of this study focuses on the search for results regarding the parameters of male fertility, the pathological aspects of the testicle and the presence of the virus in the seminal fluid.

\section{Materials AND methods}

A systematic search of the peer reviewed literature was conducted on PubMed, Google scholar and Medline databases until 30 December 2020. A combination of Medical Subject Headings (MeSH) terms was used. The keywords were: "Covid" ,"male fertility", "infertility" "sperm", "testosterone" and "quality". All titles and abstracts published in English were evaluated. All studies were considered, with the exception of those performed on animals, comments, letters, editorials and case reports. The initial search yielded a total of 47 articles. The articles deemed

No conflict of interest declared. 
Figure 1.

COVID-19 virus replication cycle.

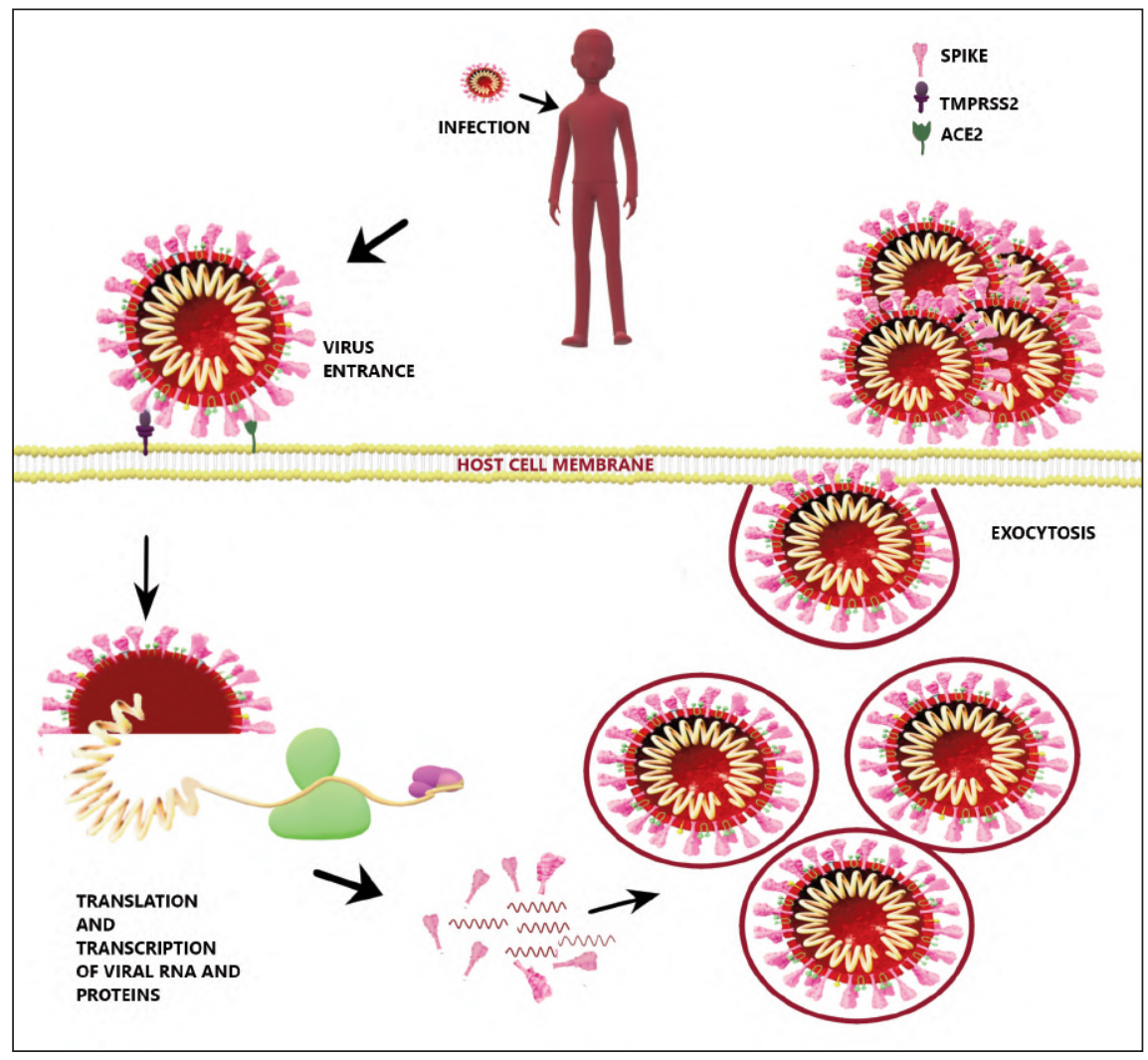

valid were selected discarding the duplicates and then the off topic articles; A total of 35 articles strictly related to our issue were finally evaluated and reviewed by the authors.

\section{Results}

\section{COVID-19}

and fertility parameters

A study published in March 2020 (9) performed on 81 patients with active disease hospitalized for moderate and severe symptoms showed that serum luteinizing hormone (LH) was significantly increased compared to a control group of 100 patients without symptoms and negative nasopharyngeal swab; furthermore, testosterone $(\mathrm{T})$ to $\mathrm{LH}$ ratio and follicle stimulating hormone (FSH) to $\mathrm{LH}$ ratio were significantly decreased. There also was a strong association in multivariate regression analysis between high levels of $c$ reactive protein ( $\mathrm{RCP}$ ) and low T/LH ratio; although there may be other factors involved, such as

Table 1.

Findings about fertility parameters

\begin{tabular}{|c|c|c|c|c|c|c|}
\hline Authors & $\begin{array}{c}\mathrm{N}^{\circ} \text { of } \\
\text { patients }\end{array}$ & $\begin{array}{l}\text { Testosterone } \\
\text { levels }\end{array}$ & 내 & FSH & $\begin{array}{l}\text { Semen } \\
\text { quality }\end{array}$ & Other findings \\
\hline Ma et al. (9) & 81 & $=/ \downarrow$ & $\uparrow$ & - & - & $\begin{array}{l}\downarrow T / L H, ~ \downarrow T / F S H, \text { associazione } \\
\text { fra alti livelli di PCR e basso T/LH }\end{array}$ \\
\hline \multirow[t]{2}{*}{ Rastrelli et al. (10) } & 31 & $\downarrow$ & - & - & - & Lower baseline levels of T nd \\
\hline & & & & & & $\begin{array}{l}\text { cff (free-testosterone) levels predict } \\
\text { poor prognosis and mortality }\end{array}$ \\
\hline Schroeder et al. (11) & 88 & $\downarrow$ & - & - & - & $\begin{array}{l}\text { High estradiol level in both } \\
\text { male e female sars-cov2 patients }\end{array}$ \\
\hline Holtmann et al. (12) & 18 & - & - & - & $\downarrow$ & $\begin{array}{l}\downarrow \text { Sperm concentration, } n^{0} \text { of } \\
\text { sperm per ejaculate, motility }\end{array}$ \\
\hline Xu et al. (13) & 39 & $=$ & $=$ & $=$ & - & $\begin{array}{l}\text { Negative correlation between high } \\
\text { estradiol levels and disease duration }\end{array}$ \\
\hline
\end{tabular}

Table 2.

Findings about pathologic aspects of the testis in COVID-19 patients.

\begin{tabular}{|l|c|c|c|c|c|}
\hline Authors & $\begin{array}{c}\mathbf{N}^{\circ} \text { of } \\
\text { patients }\end{array}$ & $\begin{array}{c}\text { Covid in testis } \\
\text { biopsy }\end{array}$ & $\begin{array}{c}\text { Lynphocytic } \\
\text { infiltration }\end{array}$ & Cytokines & Other findings \\
\hline Song et al. (14) & 13 & $\mathrm{n} 0$ & - & - & \\
\hline Shen et al. (15) & 3 & - & - & - & Ace2 levels are greather at 30 y \\
\hline Yang et al. (16) & 12 & 1 & $\begin{array}{c}\text { CD3+, CD8+ } \\
(>50 \%)\end{array}$ & - & Variable tubular damage \\
\hline Li et al. (17) & 29 & $\mathrm{~N}_{0}$ & $\begin{array}{c}\text { CD3+, CD8+ } \\
(60.9 \%)\end{array}$ & IL-6, TNF & - \\
\hline Achua et al. (18) & 7 & 3 & $+($ (in 14.2\%) & - & $\begin{array}{c}\text { Spikes at electronic microscope } \\
\text { in } 1 \text { case; high Ace2 levels } \\
\text { in patients with impaired } \\
\text { spermatogenesis }\end{array}$ \\
\hline
\end{tabular}

stress and the use of corticosteroids that may have altered the hypothalamus-pituitary-gonadal axis, the risk of hypogonadism in Covid patients was highlighted for the first time.

This was followed by other works that demonstrated the condition of hypotestosteronemia in sick and recently recovered patients $(10,11)$.

In August, a cohort study by Holtmann et al. (12) was published. Sperm samples were analyzed from 18 patients one month after recovery from Covid and 14 control cases. In patients who had Covid with mild symptoms that did not require hospitalization, there was no impact on sperm quality in the short one-month follow-up; patients who had moderate symptoms had worse sperm quality (sperm concentration, total number of sperm per ejaculate, total number of progressive motility, total number of complete motility). One among these patients also had testicular symptoms (discomfort).

$\mathrm{Xu} \mathrm{H}$ et al. (13) published in Andrology a study on 39 patients with COVID-19. The authors studied after recovery and compared to 22 controls subject. They found neither significant changes in blood testosterone, FSH and LH levels, nor associations between disease duration or severity and testosterone levels. There was a statistically significant negative association ( $p<0.001$ ) between blood estradiol levels and disease duration, as it was lower in patients who had had long illness, i.e. greater than 50 days, compared to the subgroup with normal-term disease. Three possible explanations for 
Table 3.

Findings about sperm presence of the virus.

\begin{tabular}{|l|c|c|}
\hline Authors & $\mathbf{N}^{\mathbf{0}}$ of patients & Presence of the virus and details \\
\hline Song et al. (14) & 13 & no \\
\hline Paoli et al. (19) & 1 & no \\
\hline Ning et al. (20) & 17 & no \\
\hline Li et al. (17) & 38 & Yes, 6 patients, four with active disease \\
\hline Pan et al. (22) & 34 & no \\
\hline Holtman et al. (12) & 18 & no \\
\hline
\end{tabular}

this difference have been hypothesized, identifying the possible cause in the variation in estradiol levels in the direct cellular damage from the virus, in the massive inflammatory response of the organism or in the use of some drugs, such as corticosteroids (Table 1).

\section{COVID-19 and testis pathological aspects}

In April 2020 a study by the Nanjing Medical University showed that testicular biopsy was performed on a patient who died of COVID-19, looking for viral RNA; also, sperm samples of 13 patients were analyzed. Viral RNA was not found in any of the samples (14).

In August 2020 Shen $Q$ et al. (15) observed that the expression of ACE2 in the testis is related to age, has a peak around 30 years and very low from 60 years onwards. Young men might therefore be more at risk for reproductive disorders than older men and very young children.

In European Urology Focus, Yang et al. (16) analyzed the testicles of 12 patients who died from Covid with an average age of 65 and found tissue damage in more than half of them (cellular damage and necrosis in both germinal and Sertoli cells, tubules, edema and mild inflammation of the interstitium with $\mathrm{T}$ lymphocytes). Damage to the seminal tubules was classified into three groups: absent, mild ( $<10 \% .2$ cases), moderate (10-50\%. 5 cases) and severe (> 50\%. 4 cases). These findings were compared with 5 control subjects who died for causes other than Covid. In 2 cases no tubular damage and in 3 cases mild tubular damage was found. The virus was found in the lungs of 10 out of 12 patients, but only in 1 patient was it found in the testis.

$\mathrm{Li} \mathrm{H}$ et al. (17) performed histopathological examinations on testicular and epididymal specimens, and also performed TUNEL assay and immunohistochemistry on 6 patients who died of Covid and 23 who recovered from Covid, identifying the presence of interstitial edema, congestion, red blood cells exudate in the testis and epididymis, thinned seminiferous tubules with high apoptosis rate, interstitial T lymphocytes infiltrate interstitial, $\operatorname{IgG}$ in the seminiferous ducts and increase of IL- 6 and TNF; finally they showed oligozoospermia in $39.1 \%$ of the subjects and in $60.9 \%$ of cases a leukocyte infiltrate. Subsequently, other authors analyzed the results of 6 autopsies of casualties from COVID-19 infection and 3 control cases with negative swab who had died from other causes; results were published in the World Journal of Man's Health. Also, a testicular biopsy from living with active disease was analyzed. The samples were studied by histo-morphological examination and electron microscope. Three of the six positives had abnormal spermatogenesis. One of the six patients had a testicular lymphocyte and macrophage infiltrate as from inflammation. The testicular cells of four Covid patients were examined with electron microscopy and of these 1 had visible spike particles, the same in which inflammatory infiltrate was present; spikes were also found in the testicular biopsy sample from the living patient. Using immune-fluorescence they quantitatively assessed the presence of the ACE2 receptor and showed a correlation between low expression of the ACE2 receptor in patients with normal spermatogenesis and high expression in patients with impaired spermatogenesis, i.e. pathological Sertoli cells, hypospermia, early maturation arrest, sclerosis of the seminiferous ducts (18) (Table 2).

\section{COVID-19 findings in semen}

As already mentioned, in the study by Song et al. (14) the virus was not found in the semen of 13 infected patients; twelve patients were recovering, one of them was in the acute phase of the disease.

Also, an Italian group in Rome searched for the viral RNA in the sperm and urine of a volunteer patient eight days after the virus diagnosis using PCR without findings (19); the same result has been obtained by Ning et al. (20) who searched for the nucleocapsid (N) and Orf1 genes with the PCR method in 17 sperm samples, 9 of which from patients with active disease and 8 from cured patients.

A cohort study from Beijing detected the virus in the seminal fluid of 6 out of 38 patients analyzed; two thirds of these six patients were in the acute phase of the disease while one third of them were recovering (21).

In June 2020 Pan et al. (22) searched with the PCR technique the viral genome of the virus in 34 patients, most of them about one month after diagnosis (range from 8 to 75 days). Also in this case, the $\mathrm{N}$ genes of the nucleocapsid and the ORFlab gene were searched in particular. The virus was not detected in any of them. Six patients (19\%) complained of testicular discomfort suggesting viral orchitis.

In the aforementioned Holtmann study (12) the viral RNA presence was investigated in sperm with the PCR technique, dividing patients into three groups: patients with moderate symptoms (only 4 patients), convalescents (14 patients) and control group (other 14 subjects). In none of these specimens the virus was found (Table 3).

\section{Discussion}

Viruses so far known to cause orchitis include hepatitis $B$ and $C$ viruses, human papilloma virus, flu virus, herpes simplex virus, Epstein-Barr virus, Coxsackie virus, HIV, Zika virus, Ebola virus, Arbovirus, Marburgvirus and the SARS-Cov virus (23). There are various hypotheses on the mechanism of testicular inflammation.

SARS-COV2 could, through various pathogenic pathways, increase oxidative stress, increase DNA methylation and fragmentation and decrease male fertility. Also direct cellular damage is possible through the ace enzyme on Leidig cells and spermatocytes $(24,25)$.

The blood-testis barrier (BTB) is responsible for protecting 
seminal cells from the immunity system, especially $\mathrm{T}$ lymphocytes. During active viraemia, persistent high temperature from fever can tamper with the blood-testis barrier and cause the passage of viruses. This is demonstrated by the fact that normally only a few CD3 and CD8 lymphocytes are found in the interstitium in the testes. In patients with SARS, there is an increase in $\mathrm{T}$ lymphocytes and macrophages of $4.5 \%$ and $11.7 \%$ respectively (26) and in IgG immunoreaction. This indicates that the barrier is compromised in these patients.

DNA damage is the result of apoptosis and excessive production of ROS and inflammation and can lead to an increase in the DNA fragmentation index (DFI) with consequent infertility. Since DFI is useful for assessing changes in fertility, it could be introduced as an additional method of diagnosing infertility in COVID patients (27-28).

Very interesting data comes from genetic studies; Wang et al. (29) showed that spermatogonia with an ACE2 + expression similar to lung AT2 cells are only $1.28 \%$ of all spermatogonia, while in the study by Pan et al. (22) only 4 on 6490 testicular cells studied contained both the ACE2 gene and TMPRR2; these data could indicate that in most cases the virus does not directly affect the testicle. Inflammatory cytokines, such as Il-6, may also play a role in the inflammatory response; it has been shown that its concentration is high in patients with Covid (30). Even the hypothesis of production of anti-sperm antibodies (ASA) following damage to the blood-testicular barrier may be valid $(31,32)$.

In patients with SARS-cov2, the use of inhibitors of the renin angiotensin system unfortunately does not confer protective effects on the testis in terms of cell mortality, probably not even with regard to spermatozoa (33).

The studies analyzed, although of high quality, have some limitations. First of all, the number of patients studied is limited; furthermore, the follow-up is so short that the possible future implications and the impact that SARS-COV-2 infection can have on long-term male fertility are not known.

However, it may be important to perform a Covid screening during fertility treatment, for which there are already guidelines for conduct for fertility care, identified and summarized in the study of Papathanasiou (34) from 4 publications by the European Society of Human Reproduction and Embryology (ESHRE), American Society for Reproductive Medicine (ASRM), British Fertility Society/Association of Reproductive and Clinical Scientists (BFS/ARCS) and Canadian Fertility and Andrology Society (CFAS).

For patients who are interested in sperm cryopreservation, some rules should be followed. Adiga SK (35) illustrated that the measures aimed at minimizing the risk of viral contamination in sperm cryopreservation are: blood tests before starting treatment, fully follow the correct protocols of cryopreservation and proper washing of gametes and embryos during preservation with sterile LN2.

Although in some studies the virus has been identified in the testes and there is significant evidence of hypogonadism and hypotestosteronemia, further data is needed to better understand the effects of this virus on reproductive organs, to identify how the virus eventually affects fertility parameters and to ensure that the testis is not a virus reservoir (36).
To date, no cases of virus transmission from sperm have been recorded. However active patients and patients recovered from COVID-19 are advised against donating sperm and performing assisted fertilization (37).

\section{REFERENCES}

1. Su S, Wong G, Shi W, et al. Epidemiology, genetic recombination, and pathogenesis of coronaviruses. Trends in Microbiology 2016; 24:490-502

2. Ferran Garcia J, Alvarez Gonzales JG, Corral Molina JM. Infección por SARS-CoV-2: implicaciones para la salud Sexual y reproductiva. Una declaraciòn de la posición de la Asociación Espanola de Andrología, Medicina Sexual y reproductora (ASESA). Rev Int Androl. 2020; 18:117-123.

3. John Hopkins University of Medicine, Coronavirus resource center, http://coronavirus.jhu.edu/map.html

4. Peng L, Liu J, Xu W, et al. 2019 Novel Coronavirus can be detected in urine, blood, anal swabs and oropharyngeal swabs samples. J Med Virol. 2020; 92:1676-1680.

5. Lu R, Zhao X., Li J, et. al. Genomic characterisation and epidemiology of 2019 novel coronavirus: Implications for virus Origins and Receptor binding. Lancet 2020; 395:565-574.

6. Hoffmann M, Kleine-Weber H, Schroeder S, et al. SARS-CoV-2 cell entry depends on ACE2 and TMPRSS2 and is blocked by a clinically proven protease inhibitor. Cell 2020; 181:271-80.e8.

7. Zou X, Chen K, Zou J, et al. Single-cell RNAseq Data analysis on the receptor ACE2 Expression reveals the potential risk of different human organs vulnerable to $2019 n$ CoV infection. Front Med. 2020; $14: 185-92$

8. Reis AB, Araújo FC, Pereira VM. Angiotensin (1-7) and its receptor Mas are expressed in the human testis: implications for male infertility. J Mol Histol. 2010; 41:75-80.

9. Ma L, Xie W, Li D, et al. Effect of SARS-CoV-2 infection upon male gonadal function: A single centerbased study. Medxriv March 2020, doi.org/10.1101/2020.03.21.20037267.

10. Rastrelli G, Di Stasi V, Inglese F, et al. Low testosterone levels predict clinical ad-verse outcomes in SARS-CoV-2 pneumonia patients. Androl $\neg$ ogy 2020; 00:1-11, doi.org/10.1111/andr.12821.

11. Schroeder M, Tuku B, Jarczak D, et al. The majority of male patients with COVID-19 presᄀent low testosterone levels on admission to intensive care in Hamburg, Germany: a retrospective cohort study. medRxiv May 2020, doi.org/10.1101/2020.05.07.20073817.

12. Holtmann N, Edimiris $P$, Andree M, et al. Assessment of SARSCoV-2 in human semen-a cohort study. Fertil Steril. 2020; 114:233-238.

13. Xu H, Wang Z, Feng C, et al. Effects of SARS-CoV-2 infection on male sex-related hormones in recovering patients. Andrology. 2020 Nov 5. doi: 10.1111/andr.12942.

14. Song C, Wang Y, Li W, et al. Absence of 2019 novel coronavirus in semen and testes of COVID-19 patients. Biol Reprod. 2020; 103:4-6.

15. Shen Q, Xiao X, Aierken A, et al. The ACE2 expression in Sertoli cells and germ cells may cause male reproductive disorder after SARS-CoV-2 infection. J Cell Mol Med. 2020; 24:9472-9477.

16. Yang $M$, Chen S, Huang B, et al. Pathological findings in the testes of COVID-19 patients: clinical implications. Eur Urol Focus. 2020; 6:1124-1129. 
17. Li H, Xiao X, Zhang J, et al. Impaired spermatogenesis in COVID-19 patients, EClinicalMedicine. 2020; 28:100604.

18. Achua JK, Chu KY, Ibrahim E, et al. Histopathology and ultrastructural findings of fatal COVID-19 infections on testis. World J Mens Health 2021; 39:65-74.

19. Paoli D, Pallotti F, Colangelo S, et al. Study of SARS-CoV-2 in semen and urine samples of a volunteer with positive naso-pharyngeal swab. J Endocrinol Invest. 2020; 43:1819-1822.

20. Ning J, Li W, Ruan Y, et al. Effects of 2019 novel coronavirus on male reproductive system: a retrospecative study. Preprints 2020, 2020040280, doi: 10.20944/preprints202004.0280.v1

21. Li D, Jin M, Bao P, et al. Clinical characteristics and results of semen tests among men with coronavirus disease 2019. JAMA Netw Open. 2020; 3:e208292.

22. Pan F, Xiao X, Jingtao $G$, et al. No evidence of severe acute respiratory syndrome-coronavirus 2 in semen of males recovering from coronavirus disease 2019. Fertil Steril. 2020; 113:1135-1139.

23. Khalili MA, Leisegang K, Majzoub A, et al. Male Fertility and the COVID-19 Pandemic: Systematic Review of the Literature. World J Mens Health. 2020; 38: 506-520

24. Anifandis G, Messini CI, Daponte A, et al. COVID-19 and fertility: a virtual reality. Reprod Biomed Online. 2020; 41:157-159.

25. Barbagallo F, Calogero A, Cannarella $R$, et al. The testis in patients with COVID-19: virus reservoir or immunization resource? Transl Androl Urol. 2020; 9:1897-1900.

26. Xu J, Lihua Q, Chi X, et al. Orchitis: A5. complication of severe acute respiratory syndrome (SARS). Biol Reprod. 2006; 74:410-416.

27. Santi D, Spaggiari G, Simoni M. Sperm DNA fragmentation index as a promising predictive tool for male infertility diagnosis and treatment management - Meta-analyses. Reprod Biomed Online. $2018 ; 37: 315-326$

28. Haghpanah A, Masjedi F, Alborzi S, et al. Potential mechanisms of SARS-CoV-2 action on male gonadal function and fertility: Current status and future prospects. Andrologia. 2020; e13883.

29. Wang Z, Xu X. scRNA-seq Profiling of Human Testes Reveals the Presence of the ACE2 Receptor, A Target for SARS-CoV-2 Infection in Spermatogonia, Leydig and Sertoli Cells. Cells. 2020; 9:920.

30. Mahmudpour M, Roozbeh J, Keshavarz M, et al. COVID-19 cytokine storm: The anger of inflammation. Cytokine, 2020; 133:155151.

31. Fan C, Li K, Ding Y, et al. ACE2 expression in kidney and testis may cause kidney and testis damage after 2019- nCoV infection. Preprint from medRxiv. Febr 2020 22418, doi.org/10.1101/2020. 02.12 .20022418

32. Li R, Yin T, Fang F, et al. Potential risks of SARS-CoV-2 infection on reproductive health. Reprod Biomed Online. 2020; 41:89-95.

33. Yokoyama Y, Aikawa T, Takagi H, et al. Association Of reninangiotensin-aldosterone system inhibitors with mortality and testing positive of COVID-19: Meta-analysis. J Med Virol 2020 Oct 10; 10.1002/jmv. 26588.

34. Papathanasiou A. COVID-19 screening during fertility treatment: how do guidelines compare against each other? J Assist Reprod Genet 2020; 37:1831-1835.

35. Adiga SK, Tholeti P, Uppangala S, et al. Fertility preservation during the COVID-19 pandemic: mitigating the viral contamination risk to reproductive cells in cryostorage, Reprod Biomed Online 2020; 41:991-997.

36. Dell'Atti L, Galosi AB. The role of the serum testosterone levels as a predictor of prostate cancer in patients with atypical small acinar proliferation at the first prostate biopsy. Asian J Androl. 2018; 20:15-18.

37. Maretti C, Privitera S, Arcaniolo D, et al. COVID-19 pandemic and its implications on sexual life: Recommendations from the Italian Society of Andrology. Arch Ital Urol Androl. 2020 Jun 23; 92:73-77.

\footnotetext{
Correspondence

Rocco Francesco delle Fave, MD

dellefavefrancesco@alice.it

Giordano Polisini, MD

gio.pol.93@gmail.com

Gianluca Giglioni, MD

piallu88@gmail.com

Arnaldo Parlavecchio, MD

aldopar190@gmail.com

Lucio Dell'Atti, MD, PhD (Corresponding Author)

dellatti@hotmail.com

Andrea Benedetto Galosi, MD

a.b.galosi@univpm.it

Division of Urology, University Hospital "Ospedali Riuniti",

Marche Polytechnic University

Via Conca 71, 60126 Ancona (Italy)
} 